\title{
Speed Anti-Windup PI strategies review for Field Oriented Control of Permanent Magnet Synchronous Machines
}

\author{
Jordi Espina, Antoni Arias, Josep Balcells and Carlos Ortega \\ Dep. d'Enginyeria Electrònica. Universitat Politècnica de Catalunya. C. Colom 1. 08222 Terrassa. \\ Catalunya. Spain. espina@eel.upc.edu
}

\begin{abstract}
The work presented in this paper addresses the unwanted windup phenomenon reviewing and comparing different PI anti-windup strategies employed in speed control of electric drives. The tuning process of PI controllers is usually carried out considering the system as linear and therefore disregarding its physical limits such as maximum current and voltage. To safeguard the system's integrity, the PI output is normally limited eventually causing the windup phenomenon characterized by long periods of overshoots which may even result in instability.
\end{abstract}

Firstly, this paper models and tunes the current and speed PI controllers with the root locus method for Field Oriented Control of a Permanent Magnet Synchronous Machines. Secondly, it is shown the mentioned unwanted Windup phenomenon in the speed loop. Finally, the Anti-Windup strategies are simulated and their behavior are compared when driving a Permanent Magnet Synchronous Machine with Field Oriented Control.

Finally, some experimental results obtained from a PMSM Matrix Converter-fed set up have been carried out. These results corroborate the mathematical study and simulations presented all over this paper.

\section{NOMENCLATURE}

$\begin{array}{ll}d-q & \text { Rotating frame axis. } \\ v_{d / q} & \text { Stator voltage. } \\ I_{d / q} & \text { Stator current. } \\ L_{d / q} & \text { Stator inductance. } \\ R & \text { Stator resistor. } \\ \omega_{e} & \text { Electrical speed. } \\ \omega & \text { Rotor speed. } \\ T_{e} & \text { Electrical torque. } \\ \lambda_{m} & \text { Permanent magnet flux. } \\ P & \text { Poles pair. } \\ \theta_{e} & \text { Electrical angle. } \\ \theta_{r} & \text { Rotor angle. } \\ * & \text { Superscript denotes reference. }\end{array}$

\section{INTRODUCTION}

Recently fully integrated adjustable speed drive applications have attracted more attention for a wide range of industrial applications such as hybrid electrical drives, more electrical aircrafts actuators, robots and machine tool drives. [1] [2]

With the improvements in the rare magnet materials such as (NdFeB), Permanent Magnet Synchronous Machines (PMSM) are gaining market when compared to other AC Machines due to its higher efficiency, lower inertia, weight reduction and volume[3].

Voltage Source Inverters with Pulse Width Modulation (PWM) are normally used to drive PM AC motors, but Matrix Converters (MC) can also be used, especially in high-powerdensity applications where electrolytic capacitors are inappropriate. MCs are also inherently bidirectional, draw sinusoidal input current, and have similar efficiencies to bidirectional PWM inverters. Although the MC can only output $86 \%$ of the input voltage, this is not a disadvantage if the machine is designed specially for a given application. These characteristics of the MCs have led to interest in the MC-PM AC drive for aerospace applications [4]. In addition, MCs have been exploited for integrated induction motor drives in which the converter is placed in the machine frame [5].

In order to get a fast speed and torque performance of PMSM, the Field Oriented Control (FOC) is one of the best vector control strategies [1]. Fig. 1, shows the FOC scheme (the decoupling equations have been avoided for the sake of simplicity), where three PI controllers are used, one for the outer speed control loop and two for the inner current loops. However, linear PI controllers do not have output magnitude

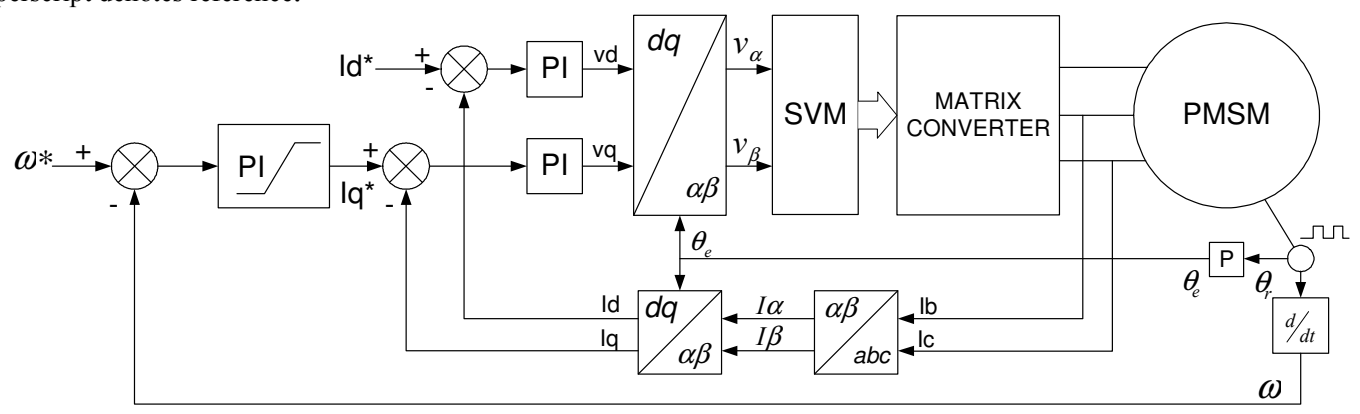

Fig. 1. Field Oriented Control of Permanent Magnet Synchronous Machines scheme with AW speed PI. 
limiters, and therefore, the output can take values relatively large and as a consequence, the real system can be damaged by the large control action [6] [7]. In order to protect PMSM, these commanded values are limited and consequently the outer speed PI accumulates error, producing a big overshoot on the speed response which, in the worst case, could even unstabilize the system; phenomenon known as Windup [6].

In order to avoid the unwanted Windup phenomenon, a maximum integrator output value will be kept within limits; strategy which is known as Anti-Windup (AW). Another solution might be to continuously tune the PI parameters to keep the response undamped at all times [8].

This paper reviews different AW strategies, providing a general classification, which is firstly divided between the methods which do depend on the saturation and the ones which do not. The latter are normally named as "PI limited" or "PI dead zone" which has the advantage of being easy to implement whereas its drawback is the tuning difficultness [9].

Methods depending on the Saturation might be divided into two different subgroups, the digital and analog ones. There are mainly two different digital approaches, the one which resets the Integral action of the PI when the Saturation is reached and the second one which holds the integral value when the Saturation is also reached [10]. The analog approaches are considered to be a bit more accurate since its AW method depends not only in the fact that the system is saturating but also considers the amount of this Saturation to proportionally compensate the integral action. Among them, the PI tracking or back calculation is based on removing from the input, of just the integral part, either the difference between the non saturated output and the saturated one multiplied by a gain factor from 0 to 1 [9] [11] [12] or just the input of the Saturation block [14]. Another approach is the analog compensation of not only the integral action but in both the proportional and integral [10].

Other more complex techniques are based on internal plant models [14], where the model output is continuously compared with the actual response. In [15], an H-infinite feedback controller is in charge of getting rid of the overshooting troubles.

This paper reviews all non model dependent AW strategies introducing a comparison of its performance when driving PMSMs with FOC using Matrix Converters.

\section{FOC OF PMSM}

Fig. 1 illustrates the speed and control loops when driving a PMSM with well known FOC scheme [1].

In motion control, the $a b c$ to $\alpha \beta$ (Clarke) and $\alpha \beta$ to $d q$ (Park) transformations are widely used, allowing the simplification of the 3 phase system to a 2 phase one, where $d$ axis current components controls directly the flux-linkage and $q$ controls torque. Moreover, SISO linear controllers might be easily applied [7].

The electrical part of PMSM is modeled in the $d q$ frame coordinate [1] by the following set of equations.

$$
\begin{gathered}
\frac{d}{d t} i_{d}=\frac{V_{d}}{L_{d}}-\frac{R}{L_{d}} \cdot i_{d}+\frac{L_{q}}{L_{d}} \cdot \omega_{e} \cdot i q \\
\frac{d}{d t} i_{q}=\frac{V_{q}}{L_{q}}-\frac{R}{L_{q}} \cdot i_{q}-\frac{L_{d}}{L_{q}} \cdot \omega_{e} \cdot i d-\frac{\lambda_{m} \cdot \omega_{e}}{L_{q}}
\end{gathered}
$$

Finally, a third equation (3) which models the electromechanical PMSM torque is needed to complete the model.

$$
T_{e}=\frac{3}{2} \cdot P \cdot\left[\lambda_{m} \cdot i_{q}+\left(L_{d}-L_{q}\right) \cdot i_{d} \cdot i_{q}\right]
$$

PMSM in standard operation do not require to create the flux since the permanent magnet $\left(\lambda_{\mathrm{m}}\right)$ already provide it and the $\mathrm{d}$ axis is aligned with it. Therefore, $q$ current component controls proportionally the motor's torque as shown in (3) if $d$ current is kept to zero.

FOC is composed of two inner current loops and an outer speed control loop. The inner loops are controlled by two identical PI. The speed control loop will be connected in cascade with torque, i.e. q-axis current, control loop as shown in Fig. 1. It must be pointed out that the current loops dynamics are faster than the speed loop and therefore, can be tuned independently.

From (1) and (2), it can be deduced that the plant dynamics just depends on the electrical pole; therefore, these two equations can be simplified, just for tuning reasons, to (4), which clearly shows a first order system.

TABLE I

MOTOR PMSM YASKAWA

\begin{tabular}{|l|l|l|l|}
\hline Output power & $200 \mathrm{~W}$ & Lq & $8.6 \mathrm{mH}$ \\
\hline Rated current & $2 \mathrm{~A}$ & Magnet flux & $0.046 \mathrm{~Wb}$ \\
\hline Voltage & $100 \mathrm{~V}$ & Rated torque & $0.64 \mathrm{Nm}$ \\
\hline Pole pairs & 4 & Rated speed & $3000 \mathrm{r} . \mathrm{p} . \mathrm{m}$ \\
\hline Stator resistance & $2.5 \Omega$ & Friction & $0.05 \mathrm{Nm} \cdot \mathrm{s}$ \\
\hline Ld & $8.3 \mathrm{mH}$ & Inertia & $0.8 \cdot 10^{-3} \mathrm{~kg} \cdot \mathrm{m}^{2}$ \\
\hline
\end{tabular}

$$
i_{d / q}(S)=\frac{1 / R}{\left(\frac{L_{d / q}}{R} S+1\right)} \cdot v_{d / q}
$$

In Fig. 2, the electrical pole $\left(-R / L_{d / q}\right)$ is placed in the root locus plane and Matlab ${ }^{\mathrm{TM}}$ computer software is used to tune the PI parameters. The conditions used to determine the PI parameters are Damping factor $\xi=0.707$ and Settling Time $T=5 \mathrm{~L} / \mathrm{R}$. Fig. 3 shows the closed electrical loop with the PI controller. 


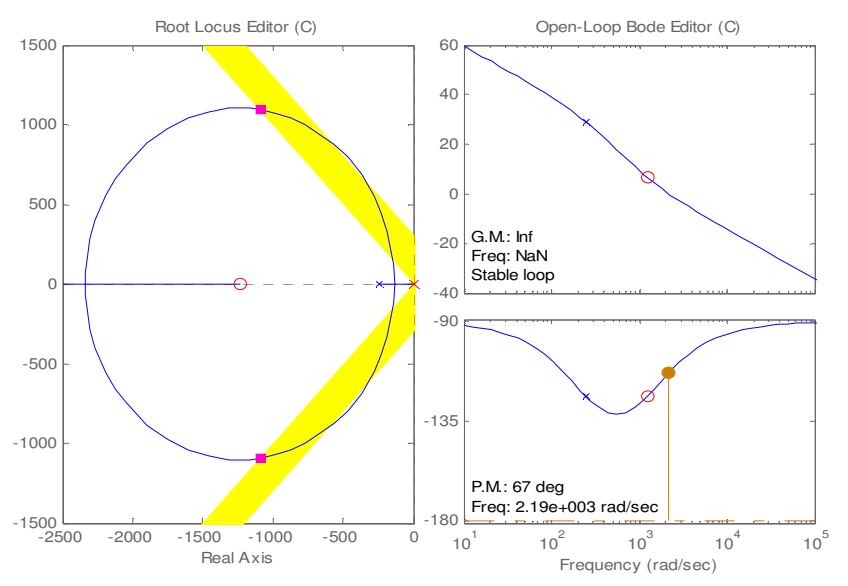

Fig. 2. Root locus current PI tuning.

The resultant $\mathrm{PI}(\mathrm{s})$ is as (5) shows:

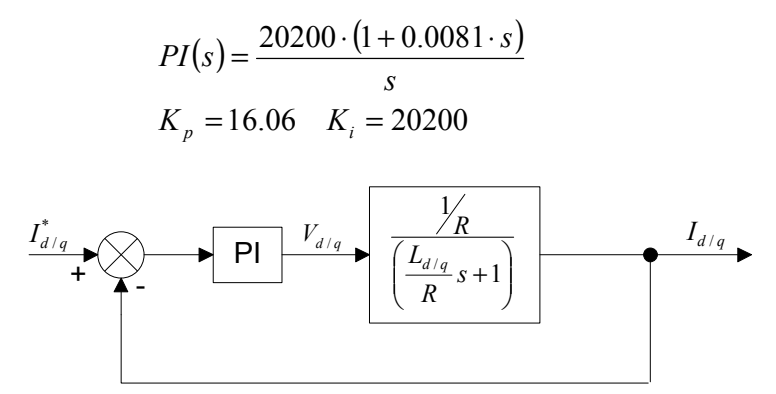

Fig. 3. PMSM Current control loop.

Similarly, the mechanical PMSM model can be modeled as a first order system as shown in (6).

$$
\omega(s)=\frac{1 / D}{\left(\frac{J}{D} \cdot s+1\right)} \cdot T
$$

From Table I the mechanical parameters have been considered to adjust the speed control with the same root locus technique. The PI obtained is given in (7)

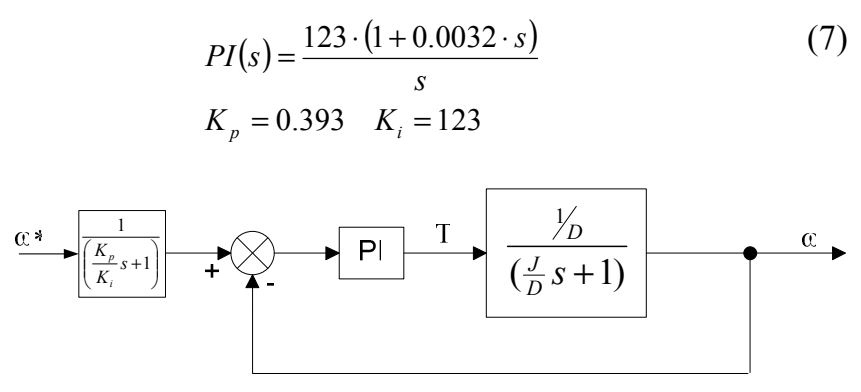

Fig. 4. PMSM Speed control loop with the pre-filter.

The speed loop will be the main control used to apply the different AW. Firstly, the speed PI together with the mechanical plant will be reduced to a pure second order system as shown in (8).

$$
T(s)=\frac{\omega_{n}^{2}}{s^{2}+2 \xi \omega_{n} \cdot s+\omega_{n}^{2}}
$$

The closed loop transfer function from the mechanical loop with the tuned PI gives not only the desired pure second order system, but also an unwanted zero, which worsens the transient response.

$$
T(s)=\frac{G}{1+G H}=\frac{\frac{K_{i}}{J}\left(\frac{K_{p}}{K_{i}} s+1\right)}{s^{2}+s\left(\frac{D}{J}+\frac{K_{p}}{J}\right)+\frac{K_{i}}{J}}
$$

The solution to have a pure second order system is to insert a pre-filter $(\mathrm{F}(\mathrm{s}))$ to get rid of the unwanted zero (10).

$$
F(s)=\frac{1}{\left(\frac{K_{p}}{K_{i}} s+1\right)}
$$

Fig. 4 shows the closed loop with the pre-filter, and then the system's behavior is equal to the desired second order like in (8).

\section{REAL SYSTEM WITH THE WINDUP PHENOMENA.}

Every real system presents some physic limitations or has some control constraints to safeguard system's integrity. The ideal control, which has been introduced above, is completely valid, although it fails when the input reference or load are deeply changed. Under these conditions, because of the Windup phenomena, the system's performance worsens and eventually it may become unstable.

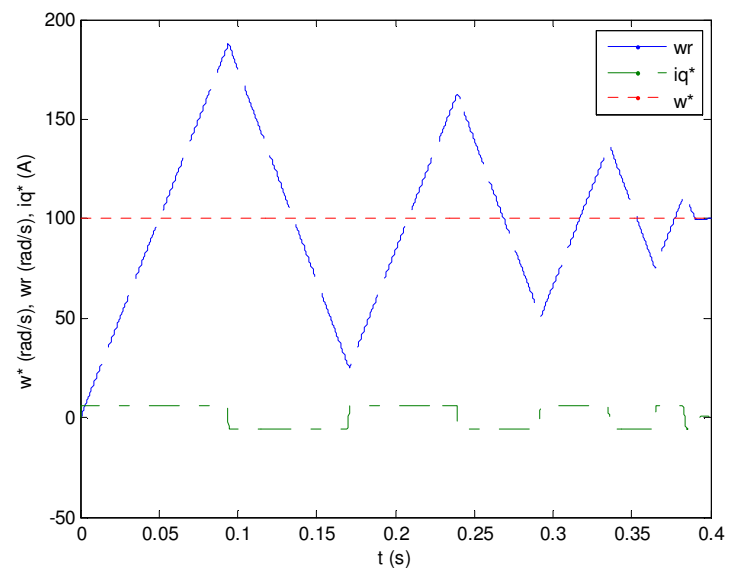

Fig. 5. Effect of current limitation.

This section shows the two types of possible unstable responses. The first one arises when the current reference command is limited to protect the system as Fig. 5 shows, and the second appears when the Voltage Source Inverter (VSI) DC-bus is restricted as Fig. 6 illustrates. 
These two limitations, implies not only an instability problem as shown in Fig. 5 and 6, but also brings the Windup problem in the integral part of the PI control.

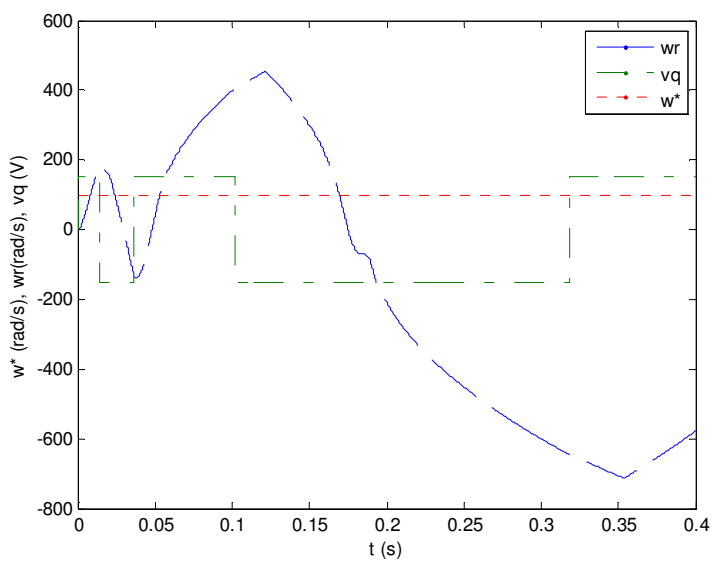

Fig. 6. Effect of D.C voltage limitation.

Next points summarize how this Windup phenomena emerge:

- Difference between input reference and the feedback generate a large error.

- PI acts in consequence applying an output value according with PI's gains. The integral action starts accumulating error, increasing its value.

- Eventually, the PI output value, mainly due to the integral accumulated magnitude, can be larger than the Saturation limit level. Under this condition the Saturation block acts providing the maximum tolerable value to the plant.

- Once the actual output reaches its reference, the error is again zero, but the integral accumulated value still remains at a value which can be much higher than the Saturation limit bringing the responses previously shown in Figs 5 and 6.

\section{BASIC ANTI-WINDUP}

The main goal of AW scheme is to avoid the over value in the Integrator, therefore the Integration output will be kept within a limited range.

Fig. 7 shows the basic AW PI compensator, where an integrator limiter has been added which does not depend on the Saturation.

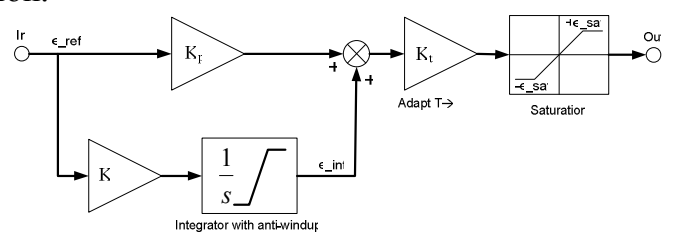

Fig. 7. AW PI-limited.

Fig. 8 shows the speed responses with and without the AW. Notice how the AW slows down the speed response when compared to the ideal one without any type of saturation. On the other hand, the overshoot has been reduced.

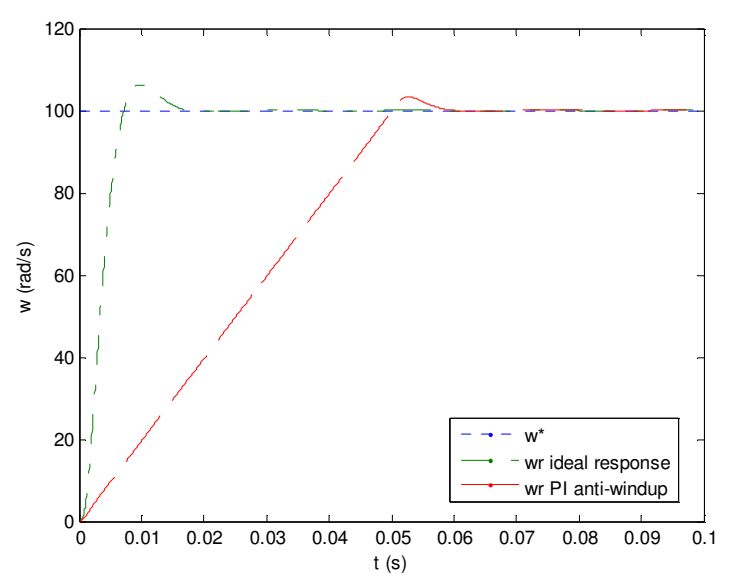

Fig. 8. Ideal and AW speed responses.

\section{DifFERENT ANTI-WINDUPS StrategIES}

In this section the structure and performance of different AW strategies are introduced. An important highlight is that the AW inserted in the speed PI loop, makes the PI and the whole speed loop non lineal. However, non-lineal PI can always be divided in three different parts, each of them being linear itself.

\section{A. AW PI with dead zone.}

In this case the limit is controlled by a dead zone element as Fig. 9 shows. Whenever the integral value does not achieve the dead zone limit, the integral value remains linear and therefore, unchanged. On the contrary, when the integral output is larger than the dead zone limit, the total integral value is reduced due to the self subtraction action [9].

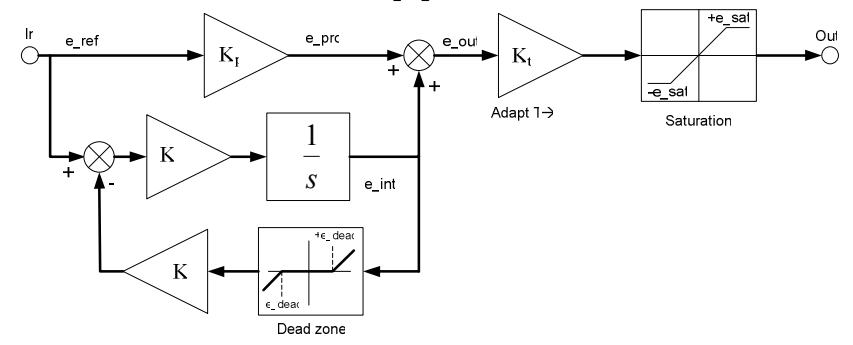

Fig. 9. AW PI with dead zone.

$$
\begin{aligned}
& \mid K_{t} \cdot e_{-} \text {out }|<| e_{\text {_s }} \text { sat } \mid \\
& \left\{\begin{array}{cl}
\text { out }(t)=K_{t} \cdot\left(K_{p} \cdot e_{-} r e f(t)+K_{i} \cdot \int e_{-} r e f(t) \cdot d t\right) & \mid e_{-} \text {int }|<| e_{-} \text {dead } \mid \\
\text { out }(t)=K_{t} \cdot\left(K_{p} \cdot e_{-} r e f+K_{i} \cdot \int\left(e_{-} r e f(t)-K_{i} \cdot e_{-} \text {int }\right)\right) & \mid e_{-} \text {int }|\geq| e_{-} \text {dead } \mid
\end{array}\right. \\
& \mid K_{t} \cdot e_{-} \text {out }|\geq| e_{\text {s sat }} \mid \\
& \left\{\text { out }(t)=e_{-}\right. \text {sat }
\end{aligned}
$$

A possible drawback may appear due to integrator's limit, which works independently of the Saturation element, so if the limit value is not correctly adjusted, the PI could have problems, such as large overshoot or undershoot as if the integral part wasn't working. 


\section{B. AW PI conditioned}

The working principle of the Fig.10's AW is really simple and robust thanks to its discrete behavior. When difference between Saturation's input and output appears, the integrator holds its last value. When the input and output Saturation difference vanishes, the integral action works again.

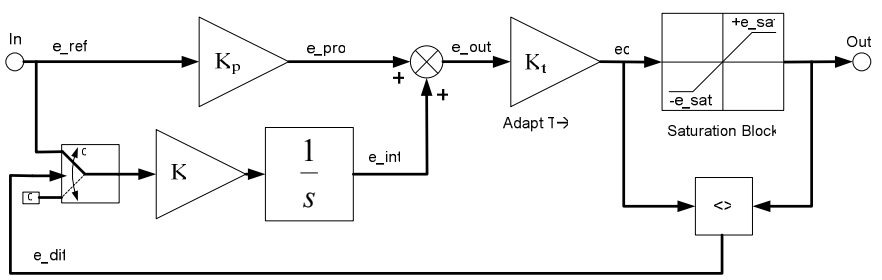

Fig. 10. AW PI conditioned.

$$
\begin{array}{cc}
\text { eo }=\text { out } & \left\{\text { out }(t)=K_{p} \cdot e(t)+K_{i} \int e(t)\right. \\
\text { eo } \neq \text { out } & \left\{\begin{array}{c}
\text { out }=e_{-} \text {sat } \\
e o(t)=K_{p} \cdot e(t)+e_{-} \text {int }
\end{array}\right.
\end{array}
$$

\section{AW PI tracking}

The AW PI shown in Fig. 11 is a bit different than the above ones. In fact, this one uses the difference between input and output Saturation block to reduce the Integrator's value [9][11].

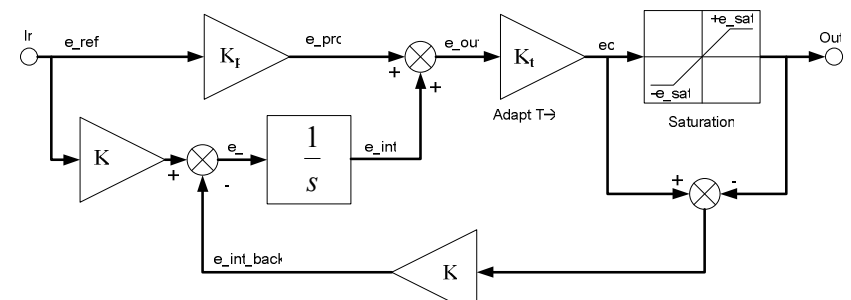

Fig. 11. AW PI tracking.

$$
\begin{aligned}
& \text { eo }=\text { out } \quad\left\{\text { out }(t)=K_{p} \cdot e(t)+K_{i} \int e(t)\right. \\
& \text { eo } \neq \text { out }\left\{\begin{array}{c}
\text { out }(t)=e_{-} \text {sat } \\
e o(t)=K_{p} \cdot e(t)+K_{i} \int\left(e(t)-\left(e o(t-\Delta t)-e_{-} s a t\right)\right)
\end{array}\right.
\end{aligned}
$$

Where: $e_{-}$sat is the maximum output value when Saturation is turned-on.

\section{AW PI tracking with gain}

The generic case of the AW PI tracking includes a gain $(\mathrm{G})$, whose margins are within 0 and 1 (14) as Fig. 12 illustrates, to vary the non linear feedback action. This gain also controls the overshoot response, increasing the gain $(G)$ get decrease the overshoot.

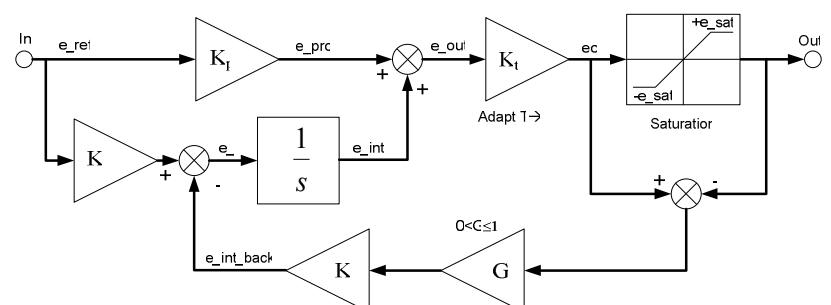

Fig. 12. PI tracking with gain.

$$
\begin{array}{ll}
\text { eo }=\text { out } & \left\{\text { out }(t)=K_{p} \cdot e(t)+K_{i} \int e(t)\right. \\
e o \neq \text { out } & \left\{\begin{array}{c}
\text { out }=e_{-} \text {sat } \\
e o(t)=K_{p} \cdot e(t)+K_{i} \int\left(e(t)-G \cdot\left(e o(t-\Delta t)-e_{-} s a t\right)\right)
\end{array}\right.
\end{array}
$$

$0<G \leq 1$

\section{Simulation ReSUlts}

All the AWs schemes shown above have been tested to analyze their behavior and a comparative has been made between them

Fig. 13 shows a zoom of the response when a speed step with no load is applied at one third of the nominal speed, i.e. 100 $\mathrm{rad} / \mathrm{s}$, where it is possible to observe accurately all different overshoots.

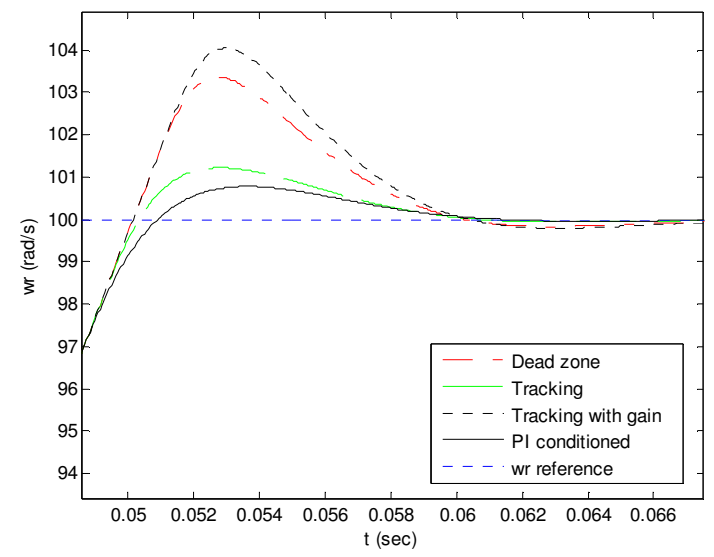

Fig. 13. AW speed PI response at one third of the nominal speed at no load.

Fig. 14, illustrates a speed reversal from nominal speed to minus one third of the nominal speed. During the start up the PMSM was at full load and it is removed at 0.3 (s) for the speed reversal.

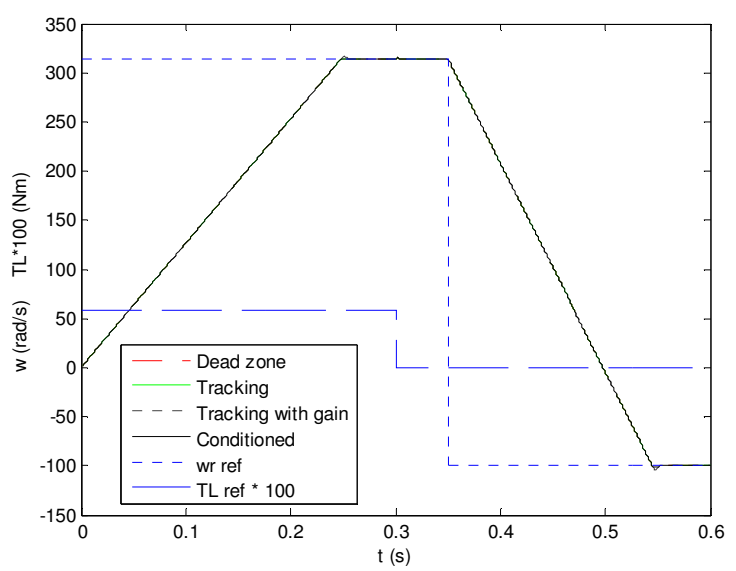

Fig. 14. AW speed PI response when speed reversal.

Fig. 15 shows with more detail the behavior of all compensators. In the right side of the graphic is possible to observe all AW PI responses to a load change. All these responses are completely linear and therefore equal due to the 
fact that the speed change is not large enough to turn-on the Saturation.

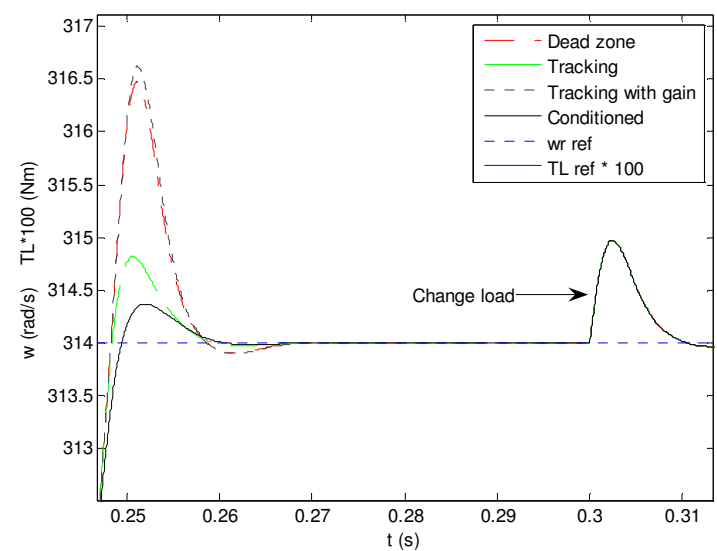

Fig. 15. Zoom of Fig. 14, zone of positive step reference. The left part is the overshoot produced by all PI after applied a step at the input. The right part is the response due to a change of load.

Fig. 16 shows the waveform response under inverse step input. The results obtained show a similar tendency that has been illustrated in Fig. 13.

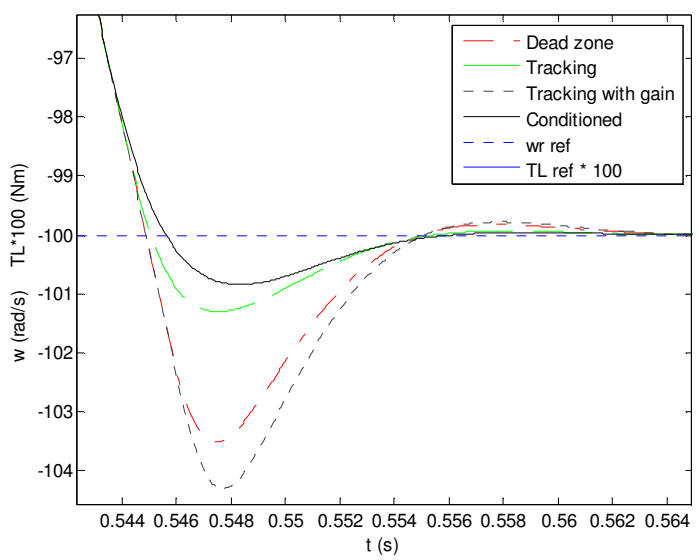

Fig. 16. Zoom of Fig. 14, response detailed of all PI to negative step or inverse reference input.

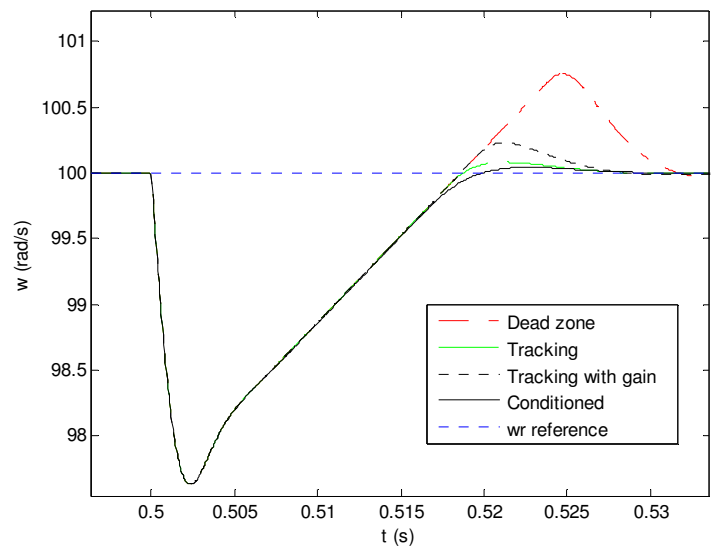

Fig. 17. AW speed PI load impact response.
Fig 17 is the response of the PIs when applying a load impact equal to 2.5 times the nominal torque.

Table II and Table III summarizes the comparison of all AW strategies under no load and full load conditions and variables which parameterize the second order system are given.

TABLE II

AW SPEED PI RESPONSE AT ONE THIRD OF NOMINAL SPEED WITH NO LOAD

\begin{tabular}{|c|c|c|c|c|}
\hline $\mathrm{TL}=0 \%$ & $\begin{array}{c}\text { Dead } \\
\text { zone }\end{array}$ & Tracking & $\begin{array}{c}\text { Tracking with } \\
\text { gain }\end{array}$ & Conditioned \\
\hline$t_{r}(\mathrm{~ms})$ & 50.2 & 50.3 & 50.2 & 50.9 \\
\hline$t_{p}(\mathrm{~ms})$ & 52.7 & 52.5 & 53.2 & 53.2 \\
\hline$M_{p}(\mathrm{rad} / \mathrm{s})$ & 3.4 & 1.2 & 4 & 0.8 \\
\hline$t_{s}(0.5 \%)(\mathrm{ms})$ & 58.2 & 56.6 & 58.5 & 56.1 \\
\hline
\end{tabular}

TABLE III

AW SPEED PI RESPONSE AT ONE THIRD OF NOMINAL SPEED AT FULL LOAD

\begin{tabular}{|c|c|c|c|c|}
\hline $\mathrm{TL}=100 \%$ & $\begin{array}{c}\text { Dead } \\
\text { zone }\end{array}$ & Tracking & $\begin{array}{c}\text { Tracking with } \\
\text { gain }\end{array}$ & Conditioned \\
\hline$t_{r}(\mathrm{~ms})$ & 79.3 & 81.5 & 79.3 & 80.6 \\
\hline$t_{p}(\mathrm{~ms})$ & 82.1 & 81.8 & 82.5 & 82.5 \\
\hline$M_{p}(\mathrm{rad} / \mathrm{s})$ & 2.4 & 0.8 & 2.5 & 0.4 \\
\hline$t_{s}(0.5 \%)(\mathrm{ms})$ & 86.9 & 84.3 & 87 & 83 \\
\hline
\end{tabular}

Where: $t_{r}$ is time rise, $t_{p}$ is time peak value, $M_{p}$ is maximum peak value and $t_{s}$ is time settling.

From Tables II and III it can be concluded that AW PIs perform load independently (despite all numbers are re-scaled due to the difference in the applied full load).

Despite all AW PI speed responses are rather similar, AW PI conditioned and AW PI tracking perform with less overshoot and have faster settling time. However, the AW PI tracking strongly depends on the plant parameters, while the AW PI is more plant and parameters independent.

On the other hand, the AW PI dead zone is the one with poorest transient performance.

\section{EXPERIMENTAL RESULTS}

The set-up used to carry out the results is based on Matrix converter driver which is driving a PMSM motor of $200 \mathrm{~W}$.

The experimental results presented only show two responses, which have got the most divergent behavior. First AW tested is AW PI Dead zone, which has the worst behavior of all introduced in this document; the second one is an AW PI conditioned which is the easiest and fastest to implement in digital systems.

Fig 18 shows the PMSM speed response at $100 \mathrm{rad} / \mathrm{s}$ step input. It is possible to appreciate the different behavior between AWs. Furthermore, if the experimental results are compared with the simulation, it can be seen the experimental result have more overshoot, two reasons, which are the fact that in $\mathrm{S}$ domain instead of $\mathrm{Z}$ domain and the lack of sampling delays. 


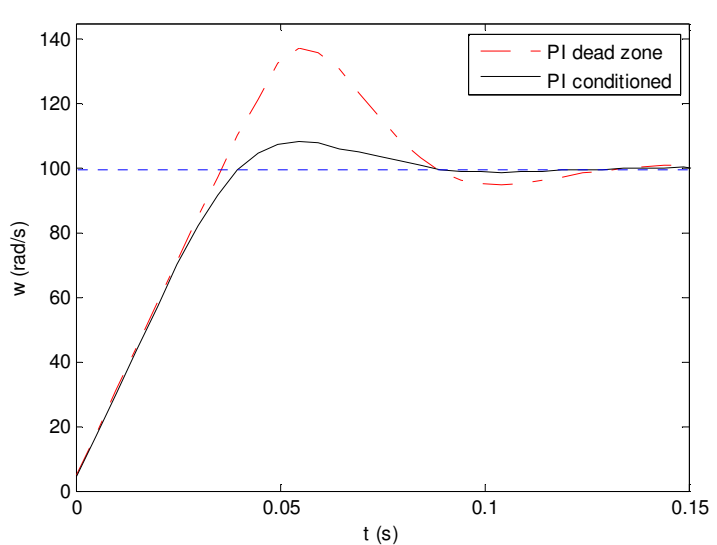

Fig. 18. Experimental AW PI dead zone and conditioned responses against speed step input reference

\section{CONCLUSIONS}

This paper has stated the well known effect of the Windup phenomenon when standard PIs are used to drive a PMSM. In such drives there are three PIs, two inner ones to control the currents and an outer one to control the speed. All three PI tunings process are clearly overviewed with the root locus technique.

This paper analyses and reviews different AW PIs to overcome the saturation problems. Simulations are carried out to compare all AW performance and a summary of the different responses is provided.

The waveforms obtained show that the best AW response is obtained with the PI tracking. Its behavior is a good balance between speed response and overshoot. However, it is necessary to know the system to tune the PI precisely. Otherwise, an improper response with an unwanted overshoot could arise.

When the plant is not known, and therefore the PI can not be tuned precisely, the PI conditioned performs with a reasonable overshoot at the expense of getting slower transient response with a bit larger time rise.

The simulation have been analyzed and verified by experimental results. On the other hand, an increase of the overshoot response has been obtained by experimental results due to different reasons: The simulation was not made in discrete domain and the sampling delays were not included. Moreover, the experimental results show good performance in Matrix Converters in order to drive small servo motors, being a good candidate in position servo systems.

\section{ACKNOWLEDGMENT}

The author acknowledges the financial support received from "Ministerio de Ciencia e Innovación de España" for realizing this work under "TEC2007-61582" research project.

\section{REFERENCES}

[1] Bimal K. Bose, Modern Power Electronics and AC Drivers. Penitence Hall PTR, October 2001.

[2] Richard M. Crowder, Electric Drives and their Controls. Clarendon Press, Oxford, 1995.

[3] T.J.E. Miller, Brushless Permanent-Magnet and Reluctance Motor Drives. Clarendon Press, Oxford, 1989.

[4] M. Aten, C. Whiltely, P. W. Wheeler, J. C. Clare, K. J. Bradley, and G. Towers, "Dynamic performance of a matrix converter driven electromechanical actuator for an aircraft rudder," in proc. IEE PEVD Conf., Edinburgh, U.K., 2004, pp. 464-468.

[5] C. Klumpner, P Nielsen, I. Boldea, and F. Blaabjerg, "A new matrix converter (MCM) for industry applications, " IEEE Trans. Ind Electron., vol. 49, no.2, pp. 325-335, Apr. 2002.

[6] Karl J. Åström and Tore Hägglund, PID Controllers: Theory, Design, and Tuning. Instrument Society of America, 1995.

[7] K. Ogata, Modern Control Engineering. Penitence Hall PTR. 2001.

[8] Yu-Sheng Lu, "Non-overshooting PI control of variable-speed motor drives with sliding perturbation observers", ELSEVIER, Mechatronics. vol.15, pp.1143-1158, March 2005.

[9] C. Bohn and D.P Atherton, "A Simulink package for comparative studies of PID Anti-windup Strategies.", IEEE/IFAC joint Symposium, 7 March 1994.

[10] K. Ohishi and E. Hayasaka, "High.Performance Speed Servo System Considering Voltge Saturation of a Vector-Controlled Induction Motor," IEEE trans on industrial electronics, vol.53, NO.3, June 2006.

[11] P. March and M. Turner, "Anti-windup Compensator Designs for Permanent Magnet Synchronous Motor Speed Regulation," The IEEE International Electric Machines \& Drives Conference, IEMDC 2007. Vol. 1, 3-5 May 2007 Antalaya. Turqkey.

[12] Xiaofeng Xu, “'Design of Current Control of Fully Integrated Surfacemounted Permanent Magnet Synchronous Motor Drive Servo Actuators", IEEE European Conference on Power Electronics and Applications, EPE 2005. pp.9, 11-14 Sept 2005 Dresden, Germany.

[13] Hwi-Beom Shin, "New Antiwindup PI Controller for Variable-Speed Motor Drives" IEEE trans on industrial electronics, vol.45. no.3, June 1998.

[14] Zhang Jinggang and Chen Zhimei, "A New Antiwindup Speed Controller for Induction Motor Drive System" International Conference on Electrical Machines and Systems, ICEMS 2001, vol.2, 18-20 Aug. 2001.

[15] Xie Dongmei, "Design of $\mathrm{H}_{\infty}$ Feedback Controller and IP-Position Controller of PMSM Servo System.", The IEEE International Conference on Mechatronics \& Automation. Vol.2, pp578-583, 29July-1Aug 2005, Niagara Falls, Canada. 